\title{
Surgical considerations in paediatric kidney transplantation: an update
}

\author{
Thilina Gunawardena* (iD, Hemant Sharma, Ajay Kumar Sharma and Sanjay Mehra
}

\begin{abstract}
Background: Kidney transplantation has established itself as the most appropriate mode of renal replacement therapy for the majority with end-stage kidney disease. Although at present this is applicable for children as well as adults, a few decades back kidney transplantation was not considered a first-line option in children. This was due to inferior outcomes following transplantation in this age group compared to that of adults. These poor results were attributed to challenges in paediatric transplantation such as the shortage of suitable donors, technical difficulties in performing a sound vascular anastomosis and the adverse effects of immunosuppressive medication on growth and development. However, current patient and graft-centred outcomes after paediatric transplantation equal or surpass that of adults. The advances in evaluation and management of specific surgical concerns in children who undergo transplantation, such as pre-transplant native nephrectomy, correction of congenital anomalies of the urinary tract, placement of an adult-sized kidney in a small child and minimizing the risk of allograft thrombosis, have contributed immensely for these remarkable outcomes.
\end{abstract}

Conclusions: In this review, we aim to discuss surgical factors that can be considered unique for children undergoing kidney transplantation. We believe that an updated knowledge on these issues will be invaluable for transplant clinicians, who are dealing with paediatric kidney transplantation.

Keywords: Paediatric kidney transplant, CAKUT, Surgical issues

\section{Background}

The first successful kidney transplantation (KT) between an adult donor-recipient pair was performed in 1954 [1]. Since then, major advances in immunosuppression, surgical technique and post-transplant medical care have substantially improved the outcomes of this procedure. These favourable results that were achieved in adults who underwent transplantation were initially not reproduced in children. They had dismal graft and patient outcomes after transplantation. Thus, children with endstage kidney disease (ESKD) were allowed to die because there seemed to be no suitable mode of long-term renal replacement therapy for them (RRT) [2].

\footnotetext{
*Correspondence: thilinamg@gmail.com

Sir Peter Medawar Unit, Royal Liverpool University Hospital, Prescot Street, Liverpool L78XP, UK
}

In 1983, Miller and colleagues published their experience in transplanting 12 children with a bodyweight $<9 \mathrm{kgs}$, and they reported long-term outcomes similar to contemporary adult transplant recipients [3]. These results reignited interest in $\mathrm{KT}$ as a suitable option for RRT in children. Presently, the short-term and longterm outcomes of kidney transplants done in children are superior or equal to that of adults, and transplantation is considered the best mode of RRT in children as well [2].

Children with ESKD are different from adults with regard to aetiology of their native kidney disease and the impact of kidney disease on their growth and development. The most common diseases that predispose to chronic renal failure in this age group are congenital anomalies of the kidney and the urinary tract (CAKUT), congenital nephrotic syndrome (CNS), cystic disease of the kidneys, renal dysplasia and aplasia. This is in contrast original author(s) and the source, provide a link to the Creative Commons licence, and indicate if changes were made. The images or other third party material in this article are included in the article's Creative Commons licence, unless indicated otherwise in a credit line to the material. If material is not included in the article's Creative Commons licence and your intended use is not permitted by statutory regulation or exceeds the permitted use, you will need to obtain permission directly from the copyright holder. To view a copy of this licence, visit http://creativecommons.org/licenses/by/4.0/. The Creative Commons Public Domain Dedication waiver (http://creativeco mmons.org/publicdomain/zero/1.0/) applies to the data made available in this article, unless otherwise stated in a credit line to the data. 
with adults who suffer ESKD mainly secondary to complications of diabetes or hypertension [4]. Children with pathologies such as intractable proteinuria due to CNS and recurrent infections due to reflux nephropathy may require native nephrectomy prior to transplantation. Those who have CAKUT need a thorough evaluation of the anatomy and the function of the urinary system. Due to their small-body proportions, finding adequate space for placement of adult-sized kidney (ASK) allografts in children can be challenging. Anastomosing the renal artery and the vein to small caliber paediatric vessels is a technically demanding task, and such anastomoses are more at risk of thrombosis. Post-operative complications after kidney transplant such as urine leak and lymphocele are seen in children as well, and they are managed according to the same principles as in adults.

In this review, we aim to address specific surgical concerns that have a bearing on the outcomes of kidney transplantation in children, namely the place of native nephrectomy, issues related to CAKUT, and surgical considerations with a special emphasis on organ placement and allograft thrombosis.

\section{Indications and timing of native nephrectomy}

Unilateral or bilateral native nephrectomy is performed in paediatric transplant candidates if the native kidneys confer a threat to patient or graft survival after transplantation [5]. The common indications for such nephrectomy in children are CNS with massive proteinuria ( $\left.>40 \mathrm{mg} / \mathrm{m}^{2} / \mathrm{h}\right)$, polyuria $(>2.5 \mathrm{ml} / \mathrm{kg} / \mathrm{h})$, hypertension refractory to medical management, recurrent urinary infections with upper tract dilatation, malignancy or conditions that may confer a high risk of future malignancy and space-limiting cystic kidney disease [5, 6].

Proteinuria associated with CNS will create a pro-coagulant state that can precipitate allograft thrombosis and venous thromboembolism. Significant proteinuria can deplete body protein reserves, which will adversely affect the child's growth. Post-transplant fluid and electrolyte management will be difficult in children with ESKD who produce large volumes of urine. They are more at risk of hypovolemia that can threaten graft perfusion [6]. Denys-Drash syndrome is a condition with a predilection for nephroblastoma and those affected will benefit from prophylactic nephrectomy before transplantation [7]. Brubaker et al. has reported better blood pressure control and reduced requirement for antihypertensive drugs in children who have had their native kidneys removed. This was considered an advantage by the authors, as children are prone to poor compliance [8].

However, there are certain disadvantages of pre-transplantation nephrectomy as well. Anuria after bilateral nephrectomy will complicate fluid, electrolyte, acid-base homeostasis and push the child towards dialysis. The production of erythropoietin and vitamin D3 by the native kidneys will completely lost, and this can potentially worsen renal anaemia and mineral bone disease [7].

Native nephrectomy can be done as a staged procedure where transplantation follows nephrectomy. Alternatively, it can be done at the time of transplantation. Another strategy is to perform a uni-nephrectomy before the transplant and to remove the remaining kidney at the time of transplant. This method preserves the function of the remaining kidney and may allow pre-emptive transplantation [5, 9]. Patients with CNS and polyuria are likely to have a staged procedure, while patients with reflux nephropathy and recurrent infections tend to undergo simultaneous nephroureterectomy at the time of transplant. According to Kizilbash et al., there were no differences in the patient or graft-centred outcomes with regard to timing of native nephrectomy [6]. The advantages of a simultaneous procedure are the ability to avoid a second hospital admission and a general anaesthetic. Additionally, it preserves the tissue planes around the aorta and the inferior vena cava (IVC) and allows easy exposure and control of these vessels for implantation of the allograft. The disadvantages of a simultaneous approach are the prolonged operative times that places the child at a higher risk of anaesthetic and surgical complications and the chances of sepsis in the immediate post-transplant period if the nephrectomy is done for recurrent infections.

Minimally invasive techniques are preferred over open surgery for pre-transplant nephrectomy in children. Trans-peritoneal and retro-peritoneal techniques have been used with equal success $[5,6]$. When simultaneous bilateral nephrectomy is performed at the time of transplantation, the approach through a midline laparotomy allows access for both procedures [6].

Medical nephrectomy by using angiotensin-converting inhibitors and non-steroidal anti-inflammatory drugs is an alternative to surgical removal of the kidneys. According to Vo et al., who published the results of such an approach in eight children with CNS, $6 / 8$ were able to avoid surgery [10].

\section{Congenital anomalies in the kidney and the urinary tract; Pre-operative evaluation and management}

CAKUT is a leading cause of ESKD in children and poses unique challenges concerning transplantation [11]. All children who are considered for renal transplantation require evaluation of their kidneys, ureters and bladder by an ultrasound scan (USS). If there is a history of recurrent urinary tract infections (UTIs), surgery or instrumentation of the urinary tract or urinary incontinence, a micturition cystourethrogram is indicated $[12,13]$. When 
bladder dysfunction is suspected, urodynamic studies are an essential component of the pre-transplant workup. These tests will provide useful information with regard to characteristics of the detrusor muscle, bladder volume, post-void residual urine volume and urine leakage [13].

Before implantation of a transplant ureter onto an abnormal bladder, the operating surgeon should be confident that lower urinary tract obstruction and neurogenic bladder dysfunction have been excluded or adequately addressed [14]. Small capacity bladders that are secondary to anuria or oliguria that do not have associated voiding dysfunction can be expected to expand in volume once the urine output increases after transplant [15].

The transplant ureter can be implanted to a neurogenic bladder in a well-motivated child who is adequately trained in clean intermittent catheterization (CIC). Anticholinergics are a useful adjunct in this situation. Urinary diversion and bladder augmentation are alternatives when the native bladder is unsuitable [14].

Bladder augmentation aims to create an adequate capacity, low-pressure urine reservoir that can be emptied by straining or CIC. The child and the caregivers should be appropriately educated and trained on the technique of CIC before embarking on this procedure. Detubularized, dilated native ureters are preferred as the first line option to increase the bladder capacity. In those who have undergone prior ureteric reimplantation, nephroureterectomy or in the presence of non-dilated ureters, segments of the ileum, sigmoid colon or the stomach are the second, third and fourth options in order of preference. Use of intestinal segments for bladder augmentation can be associated with complications such as hyperchloremic acidosis, abnormalities in calcium metabolism, growth retardation and malignant transformation. Haematuria-dysuria syndrome is an uncommon complication of gastrocystoplasty [15].

When transplanting children who have had a bladder augmentation, the ureteroneocystostomy is preferentially performed on to the native bladder. When the native bladder is unsuitable for this purpose, the transplant ureter is anastomosed to the augmented portion of the bladder [15].

Children with lower urinary tracts that are not amenable for reconstruction or those who lack the capacity for CIC will benefit from an ileal conduit. Alternatively, a continent urinary diversion such as a Mitrafanoff procedure can be considered in a child who has the capacity for CIC [12].

Timing of bladder augmentation in children with ESKD and bladder dysfunction is a controversial topic with a limited evidence base [13]. Those who advocate pretransplant bladder augmentation believe that a complex bladder reconstruction while on immunosuppression may predispose to poor wound healing and increased surgical complications. A 3-month interval is recommended when transplantation is done after bladder augmentation. During this waiting period, an anuric or oliguric patient will need regular bladder washouts to maintain its capacity and to clear the accumulated intestinal secretions. Additionally, implantation of the transplant ureter into a 'dry' bladder is such patients may precipitate urosepsis [15].

Augmentation of the bladder after transplantation potentially avoids these issues. However, reconstruction will be done while the patient is under immunosuppression. An alternative method of urinary drainage such as a suprapubic catheter will be required for adequate emptying of the bladder until it is augmented. Operating in the child's pelvis after transplantation has the potential to damage the transplant ureter and its vascular pedicle [16].

According to available data, the timing of bladder augmentation does not have an impact on the patient and graft survival after paediatric KT. The incidence of postoperative complications seems to be comparable in both these approaches $[16,17]$. So, the decision is at the discretion of the operating team, who have to consider the advantages and disadvantages on a case by case basis.

\section{Outcomes of paediatric KT on a background of CAKUT}

Historically, children with ESKD due to CAKUT were excluded from transplantation as their outcomes were considered to be extremely poor [13]. However, this has been proven incorrect, and there is conclusive evidence that children who have had kidney transplantation with a background of adequately managed dysfunctional bladder or lower urinary tract anomaly achieve comparable graft and patient survival to those who do not have such problems [18-22]. The risk of post-transplant UTI in such children appears to be significantly high, although the impact of such infection on graft and patient outcomes is not clear $[14,19]$. Long-term, lowdose antibiotic prophylaxis in post-transplant children with a reconstructed bladder will reduce the incidence of such UTIs [20, 23]. It is agreed that children who have had a KT with a bladder augmentation or urinary diversion require life-long surveillance for urological complications.

\section{Transplant surgical considerations}

Placement of an ASK in a small child can be technically challenging, but this task has been successfully achieved in children weighing less than $10 \mathrm{kgs}$ [3]. Both intraperitoneal and extraperitoneal spaces have been used for this purpose with equal outcomes [24]. Rosenthal and associates used the intraperitoneal approach when the 
bodyweight of the child was $<10 \mathrm{kgs}$. For those with a bodyweight $>15 \mathrm{~kg}$, they preferentially used extraperitoneal space. When the child weighed between 10 and $15 \mathrm{kgs}$, an individualized decision was taken after considering the size of the recipient and the donor's kidney [25]. Successful extraperitoneal engraftment of ASKs in children weighing around $8 \mathrm{kgs}$ has been reported [26].

The intraperitoneal approach is via a midline incision, and the ASK is preferentially placed in the right side of the abdomen after mobilizing the ascending colon and the terminal ileum medially to expose the common iliac vessels, aorta and the IVC. For extraperitoneal placement of the graft, a J-shaped incision is made on the right or left side of the abdomen and the peritoneum is mobilized medially and upwards to expose the recipient's posterior abdominal wall with its blood vessels [9]. The proposed advantages of the extraperitoneal technique are the reduced incidence of early and late gastrointestinal complications such as ileus and adhesive small bowel obstruction and the ability to continue peritoneal dialysis (PD) in the post-operative period for those children who are established on PD [27].

After placing an ASK in a child, tension-free primary closure of the abdominal wall can become a dilemma. Techniques such as muscle flaps and bioprosthetic meshes have been used with acceptable success to overcome this issue [28].

A technically sound vascular anastomosis is crucial for the success of the transplant. Large-diameter arteries and veins such as the aorta, IVC and the common iliac vessels are preferred as inflow and outflow vessels in children. In an infant or a very small child, there can be a marked discrepancy between the caliber of the recipient's blood vessels and the donor's renal artery and vein. As a general size comparison, the aorta in an infant will have a diameter equal to an adult renal artery and the adult renal vein can have a diameter that is three times that of an infant's IVC. When the ASK is transplanted to a small child, it is important to avoid redundancy in the vascular pedicle to avoid a kink or a twist that may precipitate thrombosis. The right renal vein is short and thin walled and leaving a cuff of donor IVC with it will make the anastomosis easier. Both the venous and arterial anastomoses are done with fine, monofilament, non-absorbable sutures. It is preferable to do at least half of the arterial anastomosis with interrupted sutures to prevent a purse string effect [14].

Sequential clamping of the recipient's vein and the artery rather than clamping them both at the start of the anastomosis will limit the time of lower extremity ischaemia and the resultant metabolic acidosis. Confirming the haemostasis of the venous suture line before performing arterial anastomosis is recommended, as it provides more access and manoeuverability for additional suture placement [14] (Table 1).

\section{Prevention of allograft thrombosis}

Allograft thrombosis is a major cause of early graft loss after paediatric KT. According to the US kidney transplant data from 1996 to 2001, it was the leading cause of graft loss in children. A history of PD, young donor and recipient age, organs from deceased donors and prolonged cold ischaemia times have been identified as risk factors for this complication [29].

Thrombophilic conditions have been associated with renal vein thrombosis in adult transplants, but large studies that address outcomes of transplantation in children with such conditions are not available [30]. In their case series, Dick et al. reported excellent results following KT in three children with inherited thrombophilic conditions. All three received perioperative anticoagulation, which was continued up to 6-12 months after the transplant [31].

Prophylactic heparin and aspirin have been used with some success for the prevention of allograft thrombosis in children who are at risk of this complication [30].

Table 1 Summary of key technical tips for allograft implantation in children

Avoid redundancy in the donor renal artery and vein
Select large-diameter inflow and outflow vessels in the recipient
Leave a cuff of IVC with the donor's right renal vein
Avoid crossing of the renal vein and the artery one over the other
At least half the arterial anastomosis should be with interrupted sutures
Clamp the IVC and the aorta sequentially for the venous and the arterial anastomosis
Cool the kidney during the anastomosis
Check haemostasis of the venous suture line before starting the arterial anastomosis

Tension-free closure of the abdominal wall (may need muscle flaps, bioprosthetic mesh placement)

Perioperative anticoagulation for children at risk of allograft thrombosis 
According to Kim and colleagues, there is no added advantage of routine perioperative anticoagulation in small children who lack risk factors for allograft thrombosis [32]. In contrast, Esfandiar et al. who used empirical treatment with heparin and aspirin in 24 children undergoing KT reported zero thrombotic events [33]. Studies that compare the efficacy and safety of antiplatelet drugs vs anticoagulants for the prevention of allograft thrombosis in children are not available at present. In addition, with regards to paediatric KT, currently, there is no consensus on the most suitable antithrombotic regimen nor who should receive such treatment [34]. So, an individualized approach considering the risks vs benefits of such therapy should be followed to determine the need for perioperative anticoagulation in children undergoing KT.

As described above, meticulous technique and attention to detail during vascular anastomosis are crucial to prevent technical errors that may predispose to thrombosis. Use of larger recipient vessels with high flow rates such as the aorta and the IVC, tilting the fluid balance of the child towards overhydration during the surgery and immediate post-transplant period are other important considerations that can reduce the risk of thrombosis [14]. Daily duplex surveillance of the allograft after paediatric KT has been recommended by some authors to facilitate the early detection of thrombotic complications [9].

\section{Conclusions}

KT is the ideal mode of RRT for paediatric patients with ESKD. Thorough pre-transplant evaluation and preparation, meticulous surgical technique and optimum posttransplant care have contributed to excellent short-term and long-term results in children after such transplants. With regard to paediatric $\mathrm{KT}$, there are multiple unique surgical aspects. Adequate understanding and appropriate attention to these issues will have a direct impact on successful outcomes.

\section{Abbreviations}

KT: Kidney transplantation; ESKD: End-stage kidney disease; RRT: Renal replacement therapy; CAKUT: Congenital anomalies of the kidney and the urinary tract; CNS: Congenital nephrotic syndrome; ASK: Adult-sized kidney; IVC: Inferior vena cava; USS: Ultrasound scan; UTI: Urinary tract infection; CIC: Clean intermittent catheterization; PD: Peritoneal dialysis.

\section{Acknowledgements}

None.

\section{Authors' contributions}

TG was involved in the conceptualization and design of the manuscript, literature survey and writing. HS, AKS and SM were involved in the critical review and modification of the article. All authors read and approved the final manuscript.
Funding

None.

Availability of data and materials

Not applicable.

\section{Declarations}

Ethics approval and consent to participate

Not applicable.

\section{Consent for publication}

Not applicable.

\section{Competing interests}

The authors declares no competing interests.

Received: 6 July 2021 Accepted: 27 September 2021

Published online: 12 October 2021

\section{References}

1. Guild WR, Harrison JH, Merrill JP, Murray J. Successful homotransplantation of the kidney in an identical twin. Trans Am Clin Climatol Assoc. 1955-1956;67:167-73.

2. Verghese PS. Pediatric kidney transplantation: a historical review. Pediatr Res. 2017:81(1-2):259-64. https://doi.org/10.1038/pr.2016.207.

3. Miller LC, Lum CT, Bock GH, Simmons RL, Najarian JS, Mauer SM. Transplantation of the adult kidney into the very small child. Techn Consider Am J Surg. 1983;145(2):243-7. https://doi.org/10.1016/0002-9610(83) 90071-5.

4. Roach JP, Bock ME, Goebel J. Pediatric kidney transplantation. Semin Pediatr Surg. 2017;26(4):233-40. https://doi.org/10.1053/j.sempedsurg. 2017.07.006.

5. Ghane Sharbaf F, Bitzan M, Szymanski KM, Bell LE, Gupta I, Tchervenkov J, et al. Native nephrectomy prior to pediatric kidney transplantation: biological and clinical aspects. Pediatr Nephrol. 2012;27(7):1179-88. https:// doi.org/10.1007/s00467-012-2115-y.

6. Kizilbash SJ, Huynh D, Kirchner V, Lewis J, Verghese PS. Timing of native nephrectomy and kidney transplant outcomes in children. Pediatr Transplant. 2020. https://doi.org/10.1111/petr.13952.

7. Fraser N, Lyon PC, Williams AR, Christian MT, Shenoy MU. Native nephrectomy in pediatric transplantation-less is more! J Pediatr Urol. 2013;9(1):84-9. https://doi.org/10.1016/j.jpurol.2011.12.008.

8. Brubaker AL, Stoltz DJ, Chaudhuri A, Maestretti L, Grimm PC, Concepcion $\mathrm{W}$, et al. Superior hypertension management in pediatric kidney transplant patients after native nephrectomy. Transplantation. 2018;102(7):1172-8. https://doi.org/10.1097/TP.0000000000002093.

9. Jalanko H, Mattila I, Holmberg C. Renal transplantation in infants. Pediatr Nephrol. 2016;31(5):725-35. https://doi.org/10.1007/s00467-015-3144-0.

10. Vos E, Koster-Kamphuis L, van de Kar NCAJ, Bootsma-Robroeks CMHHT, Cornelissen EAM, Schreuder MF. Preparing for a kidney transplant: Medical nephrectomy in children with nephrotic syndrome. Pediatr Transplant. 2020;24(4):e13703. https://doi.org/10.1111/petr.13703.

11. McEnery PT, Stablein DM, Arbus G, Tejani A. Renal transplantation in children. A report of the North American Pediatric Renal Transplant Cooperative Study. N Engl J Med. 1992;326(26):1727-32. https://doi.org/ 10.1056/NEJM199206253262602.

12. Torricelli FCM, Watanabe A, Piovesan AC, David-Neto E, Nahas WC Urologic issues in pediatric transplant recipients. Transl Androl Urol. 2019;8(2):134-40. https://doi.org/10.21037/tau.2018.06.17.

13. Pereira PL, Urrutia MJ, Lobato R, Jaureguizar E. Renal transplantation in augmented bladders. Curr Urol Rep. 2014;15(8):431. https://doi.org/10. 1007/s11934-014-0431-4.

14. Salvatierra O Jr, Millan M, Concepcion W. Pediatric renal transplantation with considerations for successful outcomes. Semin Pediatr Surg. 2006;15(3):208-17. https://doi.org/10.1053/.sempedsurg.2006.03.007.

15. Sheldon CA, Gonzalez R, Burns MW, Gilbert A, Buson H, Mitchell ME. Renal transplantation into the dysfunctional bladder: the role of adjunctive 
bladder reconstruction. J Urol. 1994;152(3):972-5. https://doi.org/10. 1016/s0022-5347(17)32633-2.

16. Taghizadeh AK, Desai D, Ledermann SE, Shroff R, Marks SD, Koffman G, et al. Renal transplantation or bladder augmentation first? A comparison of complications and outcomes in children. BJU Int. 2007;100(6):1365-70. https://doi.org/10.1111/j.1464-410X.2007.07096.X.

17. Basiri A, Otookesh H, Hosseini R, Simforoosh N, Moghaddam SM. Kidney transplantation before or after augmentation cystoplasty in children with high-pressure neurogenic bladder. BJU Int. 2009;103(1):86-8; discussion 88. https://doi.org/10.1111/j.1464-410X.2008.08081.x

18. Nahas WC, Antonopoulos IM, Piovesan AC, Pereira LM, Kanashiro H, David-Neto E, et al. Comparison of renal transplantation outcomes in children with and without bladder dysfunction. A customized approach equals the difference. J Urol. 2008;179(2):712-6. https://doi.org/10.1016/j. juro.2007.09.094.

19. Hatch DA, Koyle MA, Baskin LS, Zaontz MR, Burns MW, Tarry WF, et al. Kidney transplantation in children with urinary diversion or bladder augmentation. J Urol. 2001;165(6 Pt 2):2265-8. https://doi.org/10.1097/ 00005392-200106001-00013.

20. Capizzi A, Zanon GF, Zacchello G, Rigamonti W. Kidney transplantation in children with reconstructed bladder. Transplantation. 2004;77(7):1113-6. https://doi.org/10.1097/01.tp.0000116710.73099.8a.

21. Mendizábal S, Estornell F, Zamora I, Sabater A, Ibarra FG, Simon J. Renal transplantation in children with severe bladder dysfunction. J Urol. 2005;173(1):226-9. https://doi.org/10.1097/01.ju.0000148369.34519.86.

22. Luke PP, Herz DB, Bellinger MF, Chakrabarti P, Vivas CA, Scantlebury VP, et al. Long-term results of pediatric renal transplantation into a dysfunctional lower urinary tract. Transplantation. 2003;76(11):1578-82. https:// doi.org/10.1097/01.TP.0000090866.00241.0C

23. Adams J, Mehls O, Wiesel M. Pediatric renal transplantation and the dysfunctional bladder. Transpl Int. 2004;17(10):596-602. https://doi.org/ 10.1007/s00147-004-0784-6.

24. Muramatsu M, Mizutani T, Hamasaki Y, Takahashi Y, Itabashi Y, Kubota M, et al. Transplantation of adult-size kidneys in small pediatric recipients: A single-center experience. Pediatr Transplant. 2019;23(4): e13401. https:// doi.org/10.1111/petr.13401.

25. Rosenthal JT, Ettenger RB, Ehrlich RM, Fine RN. Technical factors contributing to successful kidney transplantation in small children. J Urol. 1990;144(1):116-9. https://doi.org/10.1016/s0022-5347(17)39386-2.
26. Furness PD 3rd, Houston JB, Grampsas SA, Karrer FM, Firlit CF, Koyle MA. Extraperitoneal placement of renal allografts in children weighing less than 15 kg. J Urol. 2001;166(3):1042-5.

27. Tanabe K, Takahashi K, Kawaguchi H, Ito K, Yamazaki Y, Toma H. Surgical complications of pediatric kidney transplantation: a single center experience with the extraperitoneal technique. J Urol. 1998;160(3 Pt 2):1212-5.

28. Donati-Bourne J, Roberts HW, Coleman RA. Donor-recipient size mismatch in paediatric renal transplantation. J Transplant. 2014;2014:317574. https://doi.org/10.1155/2014/317574.

29. McDonald RA, Smith JM, Stablein D, Harmon WE. Pretransplant peritoneal dialysis and graft thrombosis following pediatric kidney transplantation: a NAPRTCS report. Pediatr Transplant. 2003;7(3):204-8. https://doi.org/10. 1034/j.1399-3046.2003.00075.x.

30. Kranz B, Vester U, Nadalin S, Paul A, Broelsch CE, Hoyer PF. Outcome after kidney transplantation in children with thrombotic risk factors. Pediatr Transplant. 2006;10(7):788-93. https://doi.org/10.1111/j.1399-3046.2005. 00483.x.

31. Dick AA, Lerner SM, Boissy AR, Farrell CE, Alfrey EJ. Excellent outcome in infants and small children with thrombophilias undergoing kidney transplantation. Pediatr Transplant. 2005;9(1):39-42. https://doi.org/10.1111/j. 1399-3046.2004.00232.x.

32. Kim JK, Chua ME, Teoh CW, Lee MJ, Kesavan A, Hebert D, et al. Assessment of prophylactic heparin infusion as a safe preventative measure for thrombotic complications in pediatric kidney transplant recipients weighing <20 kg. Pediatr Transplant. 2019;23(6): e13512. https://doi.org/ 10.1111/petr.13512.

33. Esfandiar N, Otukesh H, Sharifian M, Hoseini R. Protective effect of heparin and aspirin against vascular thrombosis in pediatric kidney transplants. Iran J Kidney Dis. 2012;6(2):141-5.

34. Robertson JD. Pediatric transplantation: preventing thrombosis. JThromb Haemost. 2015;13(Suppl 1):S351-61. https://doi.org/10.1111/jth.12968.

\section{Publisher's Note}

Springer Nature remains neutral with regard to jurisdictional claims in published maps and institutional affiliations.
Ready to submit your research? Choose BMC and benefit from:

- fast, convenient online submission

- thorough peer review by experienced researchers in your field

- rapid publication on acceptance

- support for research data, including large and complex data types

- gold Open Access which fosters wider collaboration and increased citations

- maximum visibility for your research: over $100 \mathrm{M}$ website views per year

At BMC, research is always in progress.

Learn more biomedcentral.com/submissions 